See discussions, stats, and author profiles for this publication at: https://www.researchgate.net/publication/271988827

\title{
Simulation Analysis of In-Service Bamboo and Pine EGP Composite Flooring
}

Article · September 2014

DOI: 10.4028/www.scientific.net/AMR.1025-1026.233

CITATIONS

4

6 authors, including:

(2)

Juliana Cortez Barbosa

São Paulo State University

45 PUBLICATIONS 45 Citations

SEE PROFILE

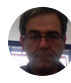

Alexandre Jorge Duarte de Souza

São Paulo State University

11 PUBLICATIONS 21 CITATIONS

SEE PROFILE
(6) José Reinaldo Moreira da Silva

Universidade Federal de Lavras (UFLA)

117 PUBLICATIONS 359 CITATIONS

SEE PROFILE

Victor De Araujo

Research Group on Development of Lignocellulosic Products (LIGNO), Itapeva, Br.. 60 PUBLICATIONS 63 CITATIONS

SEE PROFILE

Some of the authors of this publication are also working on these related projects:

Centro de Capacitação Tecnológica em Bambu View project

Projeto Cenibra SA View project 


\title{
Simulation Analysis of In-Service Bamboo and Pine EGP Composite Flooring
}

\author{
Juliana Cortez-Barbosa1, a, José Reinaldo Moreira da Silva ${ }^{2, b}$, \\ Fabiano de Alvarenga ${ }^{3,}$, Alexandre Jorge Duarte de Souza, d, \\ Victor Almeida De Araujo ${ }^{4}, \mathrm{e}^{*}$ and José Nivaldo Garcia ${ }^{5, \mathrm{f}}$ \\ ${ }^{1}$ Assistant Professor Doctor of UNESP/Itapeva. Rua Geraldo Alckmin, 519, Itapeva/SP, Brazil. \\ ${ }^{2}$ Associated Professor of UFLA. P.O. Box 3037, CEP 37200-000. Lavras/MG, Brazil \\ ${ }^{3}$ Wood Industrial Engineer of Alena Lumbermill. Pedro Rodrigues Garcia, km75, Itapeva/SP, Brazil. \\ ${ }^{4}$ Engineer and Master's Student of ESALQ/USP. Avenida Pádua Dias, 11, Piracicaba/SP, Brazil. \\ ${ }^{5}$ Titular Professor Doctor of ESALQ/USP. Avenida Pádua Dias, 11, Piracicaba/SP, Brazil. \\ ajucortez@itapeva.unesp.br, bjreinaldo@dcf.ufla.br, cfabiano-alvarenga@hotmail.com, \\ dalexandre@itapeva.unesp.br, eengim.victor@yahoo.de (Corresponding Author), fjngarcia@usp.br
}

Keywords: Bamboo, Wood, Lignocellulosic, Composites, Flooring, Mechanical testing.

\begin{abstract}
Bamboo is a renewable material that has been gaining attention in several sectors of production and research because of its potential. Its special characteristics of rapid growth, short harvest cycle, diversity and excellent mechanical properties. The objective of this work was a physical-mechanical analysis of flooring manufactured by a combination of bamboo (Dendrocalamus giganteus) laminate slats and wood (Pinus taeda) edge-glued panels (EGP). It was based on the ASTM D2394-83/1994 standard, which describes the procedures for mechanical simulation of in-service floors, such as indentation loads applied on small areas, falling ball impact, rolling load, abrasion and friction tests. The results were satisfactory when compared with those of other types of wood. The research showed lignocellulosic composite of Pine EGP with a bamboo surface, in terms of mechanical strength according the ASTM's standard, is viable and feasible. Therefore, it results that "EGP/Bamboo" composite can be successfully applied for internal floors.
\end{abstract}

\section{Introduction}

Composite materials have come to existence as long as the history of human being is known, for example, woods are natural composites surrounding mankind from the very first day [1].

Since the advent of the industrial revolution, numerous materials have been invented and combined to meet the needs of consumer society and, more recently, to address increasing environmental concerns and requirements.

Although bamboo has been used for thousands of years and it has numerous uses in several production sectors, especially by Asian peoples, its application is often limited because of its difficult mechanical processing and a lack of knowledge about its physical, chemical and mechanical properties. Another factor that hampers the advance of knowledge about the bamboo characteristics is the absence of technical standards for testing, which makes it difficult to interpret test results. This often renders it impracticable to make comparisons among studies and characterizations of different species analyzed by researchers. Tests performed on bamboo are generally based on technical standards applied to wood.

Bamboo offers many advantages compared to steel, cement and polymers, such as mechanical strength, elasticity and low weight. However, its disadvantages are dimensional diversity among species, conicity, curvature of the culm, and variable thickness of the walls of the same piece. Because it is cylindrical and hollow, connection between pieces and the difficulty of standardizing components represent one of the most limiting factors for its application in civil engineering and the production of furniture and other objects. 
However, considering the special peculiarities of this gramineous plant, such as its rapid growth, short harvest cycle, hardiness, species diversity, and especially its excellent mechanical properties, many researchers have studied this natural renewable resource and its potential for industrialization. Lima et al. [2] described the plant as having long hollow culms, which are closed at approximately regular intervals by a diaphragm in the region of the knots. The high tensile and compressive strength of its walls is comparable to that of nobler woods and its low specific weight is approximately $8.5 \mathrm{KN} / \mathrm{m}^{3}$.

Bamboo is a natural renewable resource with many advantages over other construction materials, such as its high strength, low weight, and low cost due to its high productivity and rapid growth [3].

Because of Brazil's favorable climate and soil conditions, bamboos may have significant importance against deforestation, supplying sufficient quantities of material from low-cost plantations to represent a viable alternative for housing problems. Bamboo generally reaches its maximum mechanical strength after three years, when, according to Dunkelberg [4], culm cells start to lignify and progressively form silicate, at which point it can be used for structural purposes.

Bamboo has limited uses for the production of structural materials due to factors such as its geometric configuration and its low shear strength, which does not allow for the insertion of dowel pins, rendering it unfeasible for structural designs that require strong joints or connections. Gluelaminated bamboo technology basically eliminates the problems of shear and heterogeneity of its geometry, allowing for the rational use of this material as structural elements.

Exhaustive researches have been conducted to understand the fundamental physical and mechanical properties of bamboo and to exploit it for the development of products. These possible industrial uses include the production of glue-laminated bamboo. Many wood products, such as flooring, are increasingly being replaced with layered laminates. Compared to high-density solid wood flooring, the bamboo flooring offers not only the highly valued texture of its knots but also high wear resistance and surface hardness.

Notwithstanding the satisfactory results obtained with bamboo in the production of flooring and other products, it should be noted that because of the anatomy of this gramineous plant, traditional processes employed to transform it into flat surfaces generate large quantities of waste, thus justifying new studies on the processing and industrialization of this material. Therefore, the present work sought to minimize the use of bamboo by combining its high mechanical strength with pinewood abundantly available in the region of Itapeva-Brazil in the production of floor composite.

In today's global economy, wood flooring sector requires actions to render companies more competitive and attractive in the market. Flooring production in Brazil has expanded significantly in the last few decades. This increase may be attributed in part to the growing production of "engineered" flooring, which has gained wide acceptance due to its quality.

Engineered floor is a product made of reconstituted wood panels covered with decorative wood laminate or melamine paper. The fabrication process of this type of flooring involves gluing laminate slats of varying thicknesses and different wood species on a reconstituted panel. After the gluing process, the flooring receives a finish to suit the demands of the end consumer.

According to Cardoso [5], bamboo floors are strong and durable, and are made of strips glued horizontally or vertically at the edges (Figure 1). Flooring with horizontal grade laminate is usually composed of three solid layers (slats) pressed together into a total thickness of $1.5 \mathrm{~cm}$.

Lee \& Liu [6] state that, compared with three types of commercial flooring they analyzed, bamboo flooring showed a comparable performance with regard to durability, abrasion resistance, hardness, and water absorption (24-hour immersion in water). They also concluded that the dimensional variation of bamboo flooring is more stable than red oak flooring, in addition to its greater market competitiveness and environmental correctness.

\section{Objectives}

The purpose of this work was to perform a simulation analysis of in-service bamboo flooring of Dendrocalamus giganteus combined with wooden Edge-Glued Panels (EGP) of Pinus taeda and to highlight the use of bamboo as a nobler, higher quality, harder and value-added product. 


\section{Materials and Methods}

Preparation of Test Specimens and Physical and Mechanical Tests. The test specimens for this study were prepared by combining EGP panels of pine (Pinus taeda) and strips of bamboo (Dendrocalamus giganteus). The 16-millimeters-thick EGP panels were donated by Agronomic Institute of Campinas (IAC). The bamboo strips were produced at the São Paulo State University (UNESP) at Itapeva-Brazil, and the mechanical tests were performed at labs of Federal University of Lavras (UFLA) at Lavras-Brazil with the help of forest engineering students and professors.

Fabrication of the EGP Panels. The machining and production of pine slats were monitored prior to receiving the EGP panels. Slats were oven-dried to a humidity content of $10 \%$, after which they were pressed laterally under a load of $60 \mathrm{Kgf} / \mathrm{cm}^{2}(5,88 \mathrm{MPa})$, using a high frequency hot press, roller coater glue spreaders and forming table.

Bamboo Strips. The bamboos were cut into bars of $1200 \mathrm{~mm}$ using a circular saw. Each bar was then cut with a horizontal band saw into six strips, which were machine milled to a thickness of 5 $\mathrm{mm}$. The 5-millimeters-thick strips were fed through a planer to ensure the quality of one of the gluing sides while the other side was passed through a vertical band saw. Using water resistant PVA (polyvinyl acetate) glue, the prepared strips were then glued together into sheets of laminate and pressed laterally with bench screws and clamps for 36 hours. They were then sandpapered on one side to ensure good adhesion to the EGP panels.

Preparation of the Samples (EGP Panels and Bamboo Slats). The EGP panels and bamboo laminated sheets (slats) were glued to each other with water resistant PVA glue and pressed in a high frequency press without heat for a 36-hour period. This composite panel was then cut up into 70 samples $(200 \times 100 \times 20 \mathrm{~mm})$ and 10 samples $(95 \times 95 \times 20 \mathrm{~mm})$. These latter 10 samples were used for abrasion test.

Simulation Test of In-Service Floors. The simulation tests of in-service floors were carried out to analyze the material's mechanical strength and surface for its application as a floor element.

This analysis was performed following the ASTM D 2394-83 [7] standard, which describes the test procedures performed, i.e.:

- Pin indentation caused by loads applied on small areas;

- Falling ball impact;

- Rolling load;

- Abrasion resistance;

- Determination of the coefficient of friction.

Determination of the Basic Density. The wood density is a parameter that serves to determine its quality, since it is related to several characteristics and properties required in order to use the material for a given application. One of the most practical methodologies to determine density is the ratio of dry mass to saturated volume (in grams/cubic centimeters), i.e., its basic density $\left(\mathrm{d}_{\mathrm{b}}\right)$, according to the standard ASTM D 2394-83 [7].

Saturated volume ( $\mathrm{V}_{\text {sat }}$ ) is determined (in cubic centimeters) by final dimensions of the sample immersed in water until it reaches a constant mass or shows a maximum variation of $0.5 \%$ in relation to the aforementioned measure. Dry mass $\left(\mathrm{M}_{\mathrm{s}}\right)$ is determined (in grams) from specimens dried in a chamber at a maximum temperature of $103 \pm 2{ }^{\circ} \mathrm{C}$.

An initial measurement of the sample's mass is made before it goes into the drying chamber, after which its mass is measured at 6-hour intervals until the variation is equal to or lower than $0.5 \%$ of the last measured mass. The expression (1) was used to determine the basic density of the bamboo:

$\mathrm{d}_{\mathrm{b}}=\mathrm{M}_{\mathrm{s}} / \mathrm{V}_{\mathrm{sat}}$

Acclimation Chamber. The samples were placed in an acclimation chamber, where they remained for 24 hours until they reached a constant mass, the condition required for the tests. 
Pin Indentation Test - Loads Applied on Small Areas. The pin indentation test consisted of subjecting the samples to damage by a load applied on a small area to determine their resistance to the penetration of a sharp pin or spike. This test simulates a load applied repeatedly on the same spot, such as that caused by spike heels or any other pointed objects. The test was carried out according to the ASTM D 2394-83 [7] standard, which allows for a qualitative evaluation of the indentation intensity. This test was performed twice on 13 samples, each with dimensions of $200 \mathrm{x}$ $100 \times 20$ millimeters. The samples were subjected to pin indentation by a load roller equipped with 5 -mm-diameter pins under an applied force of $890 \mathrm{~N}$, carried out in series of 10, 25 and 50 cycles, moving forward and back, applying 9 pins simultaneously. After the test, the intensity of indentation was measured with a micrometer with 0.001 millimeter of precision. The indentation was calculated based on equation (2):

$\mathrm{IECA}=((\mathrm{E} .1+\mathrm{E} .2+\mathrm{E} .3+\mathrm{E} .4) / 4)-\mathrm{I}$

Where:

- IECA: intensity of the indentation caused by the applied load;

- E.1, E.2, E.3 and E.4: external measurements;

- I: internal measurement.

Falling Ball Impact Test. The test was performed according to the ASTM D 2394-83 [7] standard, subjecting the samples to the impact of a ball falling from 12 different heights. The test started at a maximum height of $1800 \mathrm{~mm}$ and was reduced by $150 \mathrm{~mm}$ in each subsequent stage of the test. Each sample was hit three times by the falling ball from the same height but at different points. The tests were carried out at 12 heights with 2 repetitions, on a total of twenty-four $200 \times 100 \times 20 \mathrm{~mm}$ samples. In this test, the samples are supported on a firm base perpendicular to the falling ball in order not to influence the result. The falling ball impact device has a metal ball of 53.5 grams and a diameter of $51 \mathrm{~mm}$.

For this test, the sample is placed on the machine and covered with a sheet of carbon paper so that the falling ball marks the exact spot where it has landed, providing a visual view and allowing for the result to be measured. The ball is held at the desired height by an electromagnet and drops when the electromagnet is switched off, marking the spot where it lands on the sample. Impact was measured at 5 points using a micrometer, which allowed for an evaluation of the impact intensity. Impact was calculated based on equation (3):

$\mathrm{IEEC}=((\mathrm{E} .1+\mathrm{E} .2+\mathrm{E} .3+\mathrm{E} .4) / 4)-\mathrm{I}$

Where:

- IEEC: intensity of the impact caused by the falling ball;

- E.1, E.2, E.3 and E.4: external measurements;

- I: internal measurement.

Rolling-Load Test. The test was performed following the ASTM D 2394-83 [7] standard, using samples with dimensions of $200 \times 100 \times 20 \mathrm{~mm}$ (millimeters), whose surfaces were subjected to a rolling load simulating dragging furniture (pianos, beds, etc.). The test was performed with two repetitions, each involving 10 samples. The load was applied directly on a roller which applied a force of $890 \mathrm{~N}$.

The depth of indentation produced by repeated passages of the roller's pins indicates the resistance of the material. The samples were arranged side by side at an angle of 45 degrees in relation to the moving load. These samples were subjected to 10, 25 and 50 cycles, and the intensity of indentation of the roller's pins was measured in each cycle using a micrometer with $0.001 \mathrm{~mm}$ of precision. Each cycle represents one forward and backward movement of the roller.

Abrasion Resistance. Abrasion is the result of surface wear of a floor caused by people walking on it and by contact with objects. This test was performed according to the ASTM D 2394-83 [7] standard, using 10 samples with dimensions of $95 \times 95 \times 20 \mathrm{~mm}$. 
The samples were subjected to the constant contact of 500 grams of "H-18" abrasive wheel operating at 72 cycles/minute. One thousand cycles were applied, pausing at 100-cycle intervals to record variations in mass and at 200-cycle intervals to record wear intensity, which was measured with a micrometer.

The wear was calculated based on the difference between the mean values of the external measures and the internal measure. In accordance with the standard, the abrasive wheel was reconditioned by sanding and the abrasive wheel was cleaned to prevent removed bamboo particles from clogging wheel's abrasive material.

Determination of the Coefficient of Friction. The test to determine the coefficient of friction was also based on the ASTM D 2394-83 [7] standard to calculate the samples' static and dynamic friction, using a universal testing machine linked to a computer for the acquisition of force-intensity data and friction coefficients, and the creation of a force versus coefficient graph.

Samples were subjected to an $11.5 \mathrm{~kg}$ load block, whose direct contact with the sample consisted of a block of leather resembling heel of a shoe. The $200 \times 100 \times 20 \mathrm{~mm}$ samples were sandpapered, and given a coating of sealant and wax in order to render their characteristics as similar as possible to those of a real floor. The samples were then placed in the universal testing machine equipped with a flexible cable, a pulley, an iron artifact that is placed on the sample and a load cell.

The coefficient of static friction is determined from the maximum force required to move the block from a stationary position; thus, static friction is manifested by the force acting in the opposite direction to that of the translation movement. However, there is a limit for the value of the maximum force of static friction: if the force exerted on the block resting on the sample exceeds this value, the block will begin to move.

Intensity of maximum force of static friction $\left(\mathrm{F}_{\mathrm{e}, \max }\right)$ is related to characteristics of the surfaces in contact with each other, translated by the coefficient of static friction $\left(\mu_{\mathrm{e}}\right)$ and the value of the compressive force between two surfaces in contact with each other, which in this case is the weight of the block $(\mathrm{N}=11.5 \mathrm{~g})$. This coefficient was calculated using equation (4):

$\mathrm{F}_{\mathrm{e}, \max }=\mu_{\mathrm{e}} \mathrm{x} \mathrm{N}$

When the block begins to move, a constant force must continue to be exerted to maintain this movement. This is due to the action of the so-called force of dynamic friction or slipping.

To keep the block moving uniformly, the intensity of applied force must be equal to the value of the force of dynamic friction. Intensity of the force of dynamic friction $\left(F_{d}\right)$ is also related to the characteristics of the surfaces in contact with each other, translated by the coefficient of dynamic friction $\left(\mu_{\mathrm{d}}\right)$ and value of compressive force among surfaces in contact as expressed by equation (5):

$\mathrm{F}_{\mathrm{d}}=\mu_{\mathrm{d}} \mathrm{xN}$

\section{Results and Discussion}

Basic Density. In addition to indicating quality of wood, basic density is an excellent parameter for analyzing the feasibility of its use for a variety of purposes. Unlike the specific mass of wood, that of different bamboo species does not vary significantly.

The average values basic densities vary from 0.60 to $1.00 \mathrm{~g} / \mathrm{cm}^{3}[8,9]$ or from 0.7 to $0.84 \mathrm{~g} / \mathrm{cm}^{3}$ $[10,9]$, depending, among other factors, on the sampling site, moisture content and position of culm in the clump. The density of bamboo used in this work (Dendrocalamus giganteus), which was determined based on the ratio of dry mass to saturated volume, was $0.67 \mathrm{~g} / \mathrm{cm}^{3}$.

Pin Indentation Test - Loads Applied on Small Areas. According to Martins [11], pin indentation test involving loads applied on small areas simulates pressure exerted on a floor by the heels of shoes worn by people walking on it, especially spike heels which have small areas of contact with floor. The bamboo laminate on the EGP panel ensures a surface that, due to its density, is more resistant to the penetration of pins. 
This finding is consistent with the results obtained by Kollmann \& Cotê [12], who found that hardness of North American and European woods is directly proportional to the density of the wood. The results of the indentation produced by the pins in the indentation test, in the two analyses, showed average values of 0.082 and $0.094 \mathrm{~mm}$, resulting in a final mean (weighted) intensity of $0.088 \mathrm{~mm}$.

It should be noted that pin indentation test serves for qualitative analyses of a material and that the result obtained can be altered, of necessary, by a better finish of the product for application as flooring. However, although this analysis is qualitative, the results and measurements obtained with the micrometer can be compared to those of other tests on different species, using the same scientific methodology and performed in the same laboratory.

Falling Ball Impact Test. The falling ball impact test was carried out at 12 different heights and the resulting indentations were measured. Based on these measurements, a first-order function graph was built starting from the tendency line of the points (Figure 1).

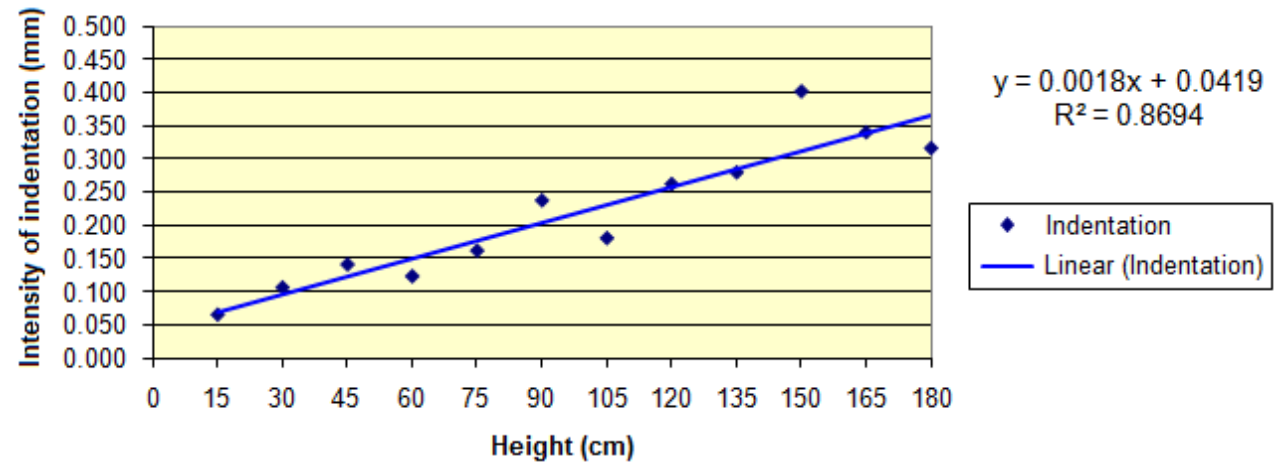

Fig. 1 Correlation between intensity of indentation and height in falling ball impact.

The first-order equation was obtained from the tendency line, and the intensity of indentation was determined using a height of 180 centimeters as the unknown of the solution, according to the ASTM D 2394-83 [7]. Hence, by substituting the height of 180 centimeters in the expression, the indentation intensity was found to be 0.366 millimeters.

Rolling-Load Test. The mean depression of the two analyses and the corresponding points was determined based on the rolling load test, which shows depressions produced in each cycle (corresponding to one forward and back motion of the roller). Figure 2 was then built using these mean values of intensity of depression as a function of the number of cycles. This analysis indicated that in test, the samples underwent a mean deformation of $0.384,0.529$ and $0.581 \mathrm{~mm}$ in the 10th, 25 th and 50th cycles, respectively.

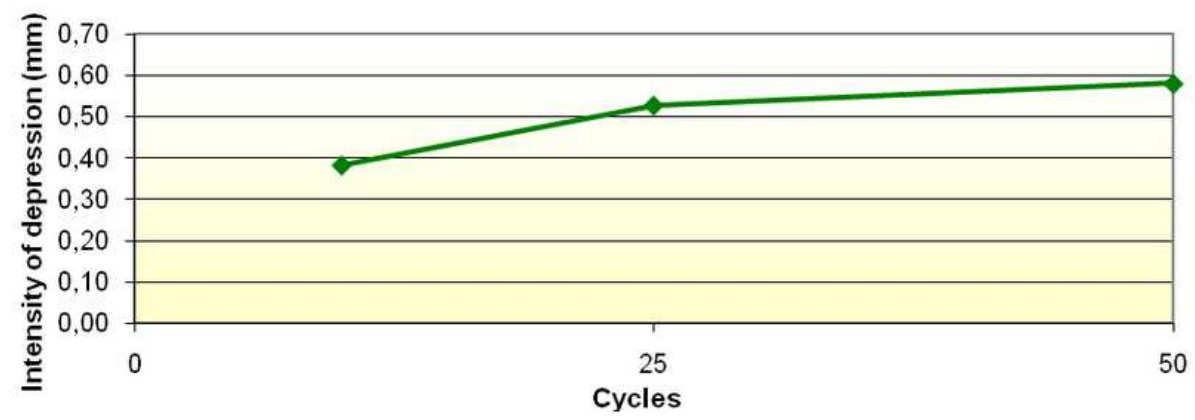

Fig. 2 Intensity of depression as a function of the number of rolling-load cycles.

Abrasion Resistance Test. The wear of a floor is determined by its ability to withstand mechanical friction such as rubbing, scraping or erosion caused by objects or people moving over its surface. Abrasion resistance is one of the most important factors in determining the performance of the service life of flooring. Abrasion causes the removal of material by action of hard particles rubbing 
surface or between two surfaces in relative movement, or by the presence of protrusions on one or both surfaces.

Viecili [13] asserts that abrasion resistance is extremely important when traffic consists of heavy load moving equipment with rigid wheels, particularly metal wheels. In this test, the mass loss values (in grams) were determined at every 100 cycles.

The mean values of the variation in mass of the samples in the cycles were then calculated to build the Graph of Figure 3. Values of the depressions caused on the samples were determined at every 200 cycles, after which the mean values of the depressions produced in the cycles were calculated to build the Graph of Figure 4.

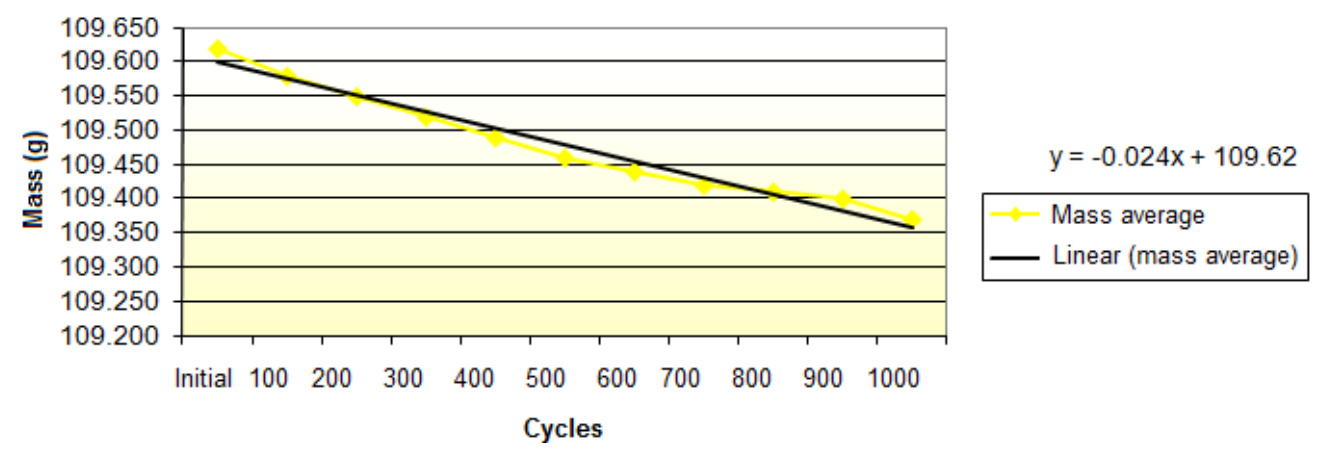

Fig. 3 Mean mass as a function of the number of abrasion cycles.

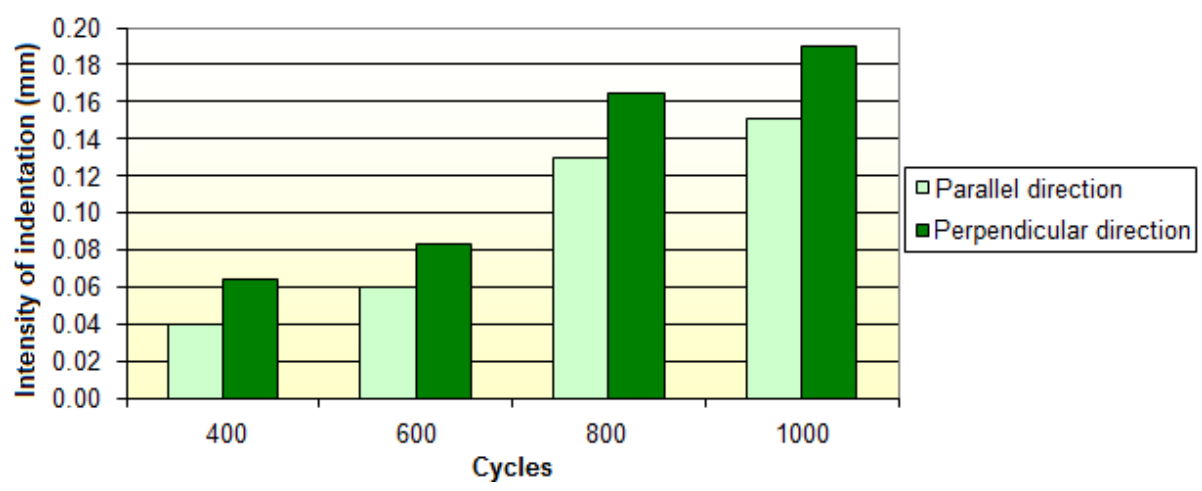

Fig. 4 Depression vs. cycles in relation to the direction of the fibers in abrasion test.

It was found that amount of abrasion at the end of 1000 cycles varied according to the position of the fibers. The mean depression in the direction parallel to the fibers was $0.151 \mathrm{~mm}$ and in the perpendicular direction $0.190 \mathrm{~mm}$.

Determination of the Coefficient of Friction. The coefficient of friction is defined by opposing forces acting at the contact surfaces of two bodies sliding over each other. The mean values of the coefficients of static and dynamic friction of the samples were, respectively, 0.31 and $0.24 \mathrm{~mm}$.

\section{Conclusions}

In the composite floor, all the mechanical properties evaluated correspond to the bamboo material, because all the surface stresses were applied on it, since the layer of EGP panel served simply as underlying support to give the composite the necessary stiffness. The bamboo slats were glued randomly, i.e., without orientation with respect to their inner or outer side, which influenced the results since the higher concentration of fibers on the outer side provides higher density, and hence, greater resistance.

Bamboo species used in this research showed a lower density than that reported by other authors. This could be attributed to the fact that the basal portion of the culms (with lower density) was used in order to attain higher productivity in machining the bamboo, due to the greater thickness of the 
walls in this area. Nevertheless, in general, the tested samples presented results comparable to those of wood floors whose densities are similar to those of the bamboo samples used in this research.

From the results of the analysis of resistance carried out according to the standard ASTM D 239483 [7], it was inferred that the combination of the pine EGP panel and the surface of bamboo Dendrocalamus giganteus is feasible in terms of the characteristics of mechanical strength, and this composite can be widely used as an element for internal floors. Nevertheless, the tests performed in this study should be repeated in order to compare other different bamboo species of higher density with more types of flooring available on the market, such as engineered wood and even imported bamboo flooring. Moreover, further researches are also needed focusing on the bamboo processing and industrialization to attain a higher yield in the manufacture of laminates and new composites that make better use of bamboo by-products, thus minimizing raw material wastage.

\section{References}

[1] A. Varvani-Farahani: Appl. Compos. Mat. Vol. 17, No. 2, (2010), p. 63

[2] H.C. Lima Jr, P. R. Dalcanal, F.L. Willrich and N.P. Barbosa: International conference of sustainable construction into next millenium: environmentally friendly and innovative cement based materials, (2000), p. 394.

[3] W. Liese: Characterization and utilization of bamboo: Production and utilization of bamboo and related species, Proc. XVIII IUFRO World Congress, Kyoto University, (1986), p. 11

[4] K. Dunkelberg: Bamboo as a building material. University of Stuttgart (1985), p. 431

[5] M.L.J. Cardoso: Recommendations for design of laminated bamboo flooring glued - BLC. [Thesis], Federal University of Bahia, (2008), 159 p.

[6] A.W.C. Lee and Y. Liu: J. Forest Prod. Vol. 53, No. 6, (2003), p. 23

[7] ASTM - American Society for Testing and Materials: ASTM D 2394-83 - Annual book of ASTM standards, ASTM, (1994), 608 p.

[8] A.P. Schniewind: Concise Encyclopedia of Wood and Wood-Based Materials, Materials Science and Engineering, MIT Press, (1989), 374 p.

[9] A.L. Beraldo, A. Azzini, K. Ghavami and M.A.R. Pereira: Bambu - Characteristics and Applications, In: W.J. Freire and A.L. Beraldo: Technologies and Alternative Building Materials, 1st ed., UNICAMP, (2003), p. 25

[10] C.H. Xuhe and Y. Kelin: Composite products from non-wood fibrous raw materials, Proc. XIX IUFRO World Congress, (1990), China Wood Industry, (1991), p. 41

[11]M. Martins: Simulation test for use on floors Eucalyptus cloeziana F. Muell, microcorys F. Muell Eucalyptus and Corymbia maculata Hook, [Thesis], UFLA, (2008), p. 59

[12]F.F.P. Kollmann and W.A. Cotê: Principles of wood science and technology. Springer Verlag, (1968), p. 592

[13]F.A. Viecili: Influence of surface hardening cementitious use of the abrasion resistance of industrial concrete floors, [Thesis], UFRGS, (2004), p. 99 
Advanced Materials, Structures and Mechanical Engineering

10.4028/www.scientific.net/AMR.1025-1026

Simulation Analysis of In-Service Bamboo and Pine EGP Composite Flooring 10.4028/www.scientific.net/AMR.1025-1026.233

\section{DOI References}

[1] A. Varvani-Farahani: Appl. Compos. Mat. Vol. 17, No. 2, (2010), p.63.

http://dx.doi.org/10.1007/s10443-009-9107-5 